\title{
Behaviour of implant-bearing overdenture materials with a change in number and position implants; what happen with all on four protocols?
}

\begin{abstract}
A bibliographic review was carried out on the evidence published in the last 10 years, 2006-2017 on four alternative therapeutic options for a complete prosthesis in a mandibular toothless patient: overdenture on 1, 3 or 4 implants, and the All on protocol Four. For this purpose, one of the main biomedical sciences researchers was used, such as PubMed, through the library of the Faculty of Medicine and Health Sciences of the University of Oviedo. Throwing a total of 1539 results, which after the different filters year of publication, percentile of the journal and keywords were bounded to 39 articles.
\end{abstract}

Keywords: implant overdenture, all on four protocol, stress, implant distribution
Volume 8 Issue I - 2017

\author{
Marcos Moradas Estrada,' Beatriz Alvarez \\ Lopez $^{2}$ \\ 'Department of Conservative Dentistry, University of Oviedo, \\ Spain \\ ${ }^{2}$ Odontologist primary health care area I of the Health Service \\ of the Principality of Asturias, Spain
}

Correspondence: Marcos Moradas Estrada, Department of Conservative Dentistry, University of Oviedo, Spain, Emailmarcosmords@gmail.com

Received: May 29, 2017 | Published: August 18, 2017

\section{Introduction}

The demand for greater prosthetic stability by patients with conventional full dentures has been and is a constant in daily clinical practice. This, together with the presence of important bone atrophies or limiting economic factors, which contraindicate the planning of an 'all fixed' rehabilitative treatment, has made overdentures the prostheses of choice in many cases. The overdentures are complete and complete denture-filled arcade prostheses that are a valid and reliable indication option for a total e dentulous of one or the other arch, more after negative experiences with a complete removable prosthesis. ${ }^{1}$ Although a fixed prosthesis is always preferable, it is known that the aesthetics of edentulous patients with moderate to advanced bone loss improves with an overdenture when compared to a fixed restoration, so much so that the labial support and Facial defect is often the deciding factor between a fixed prosthesis or an overdenture, since the fixed prosthesis has a limited capacity to compensate for vertical and horizontal bone loss, while the overdenture easily replaces both vertical and horizontal alveolar defects Being able to restore the lost tissue volumes over the years, restoring the correct relationships between the lip, nasogenic line and base of the nose, the basis of the aesthetics of rejuvenation that most patients seek. ${ }^{2,3}$ Multiple evidence ${ }^{1-4}$ has shown that overdentures are a predictable treatment modality, especially in edentulous patients with adjustment problems for a conventional full denture. So much so, that from the beginning of the implant era, overdentures were indicated and the first articles on its success were published with mandibular subperiosteal implants or implants in a stabilized root shape and loaded immediately on the anterior part of the mandible. ${ }^{2}$ However, although implant-retained overdentures solve most of the problems that might not solve a complete mandibular prosthesis, they are not without drawbacks and a great number of articles show this, ${ }^{5,6}$ and the results of the results obtained in this study were similar to those obtained in the present study. ${ }^{7}$ Unresolved questions regarding the number of implants to be used, their position and arcade distribution, In relation to the transmission, distribution and location of stress to the support ground (implants and peri-implant bone) and prosthetic elements caused by functional or non functional loads depending on the number and distribution of implants regardless of the morphological and bone quality characteristics of the lower arch: questions that require answers and to date have not been clarified with sufficient scientific evidence. Regarding the number and arrangement of the implants, it has been extensively analyzed to find the best relationship between cost-effectiveness, using two, three, four and even a single implant to retain a mandibular overdenture. At present there is a certain consensus in admitting two implants placed in a suitable position, are sufficient to obtain an overdenture with a good retention and stability for the masticatory function. For all other questions, the evidence is not so obvious and there are hardly any articles in the dental literature.

\section{General and specific objectives}

The general objective of this work is to determine which restoration is the most appropriate before mandibular edentulous patients using four implants: fixed or removable option.

\section{Specific objectives}

a. To quantify the stress transmitted to support ground and other constituent elements of a removable prosthetic restoration as one under Compare where a greater deformation is exerted before each type of restoration.

b. To determine the biomechanical and perimplant health risks before both options, removable or fixed.

c. Compare the long-term evidence of options, comparing perimplantitis and fracture of prosthetic components.

d. Implantorretened overdentures: constituent elements, number of implants parts and types. 
An overdenture consists basically of artificial teeth, an acrylic base with or without metallic reinforcement and a retention system that attaches it to the implants, ${ }^{8}$ and two types of relationships can be established with the support terrain: overdentures Implantoretenidas and mucosoportadas and implantoretenid and implantosoportadas overdentures. It follows, therefore, that it is particularly important, among other things, to design and correct the prosthesis and, secondly, to select the type of attachment to be used. They can be classified with a reductionist criterion in axillae, like those of our study, and bar type. ${ }^{9}$ The main reason for choosing the axial type and specifically the subtype locator will be, in addition to the simplicity in its technique, the biomechanical advantages and stability that the restoration will grant. In implant-retained and mucosal-supported overdentures, the prosthesis is essentially retained by the implants and basically supported by the edentulous basal area and to a lesser extent by the implants. With this design, the prosthesis has retention and some resilience allowing some movements such as intrusion of the prosthesis and some other depending on the anchoring system, which theoretically should reduce the overload on the implants. ${ }^{10}$ In this line, with the objective of canceling or minimizing the overload on the support ground (implants and osteofibromucosa) provoked by uncontrolled prosthetic movements, we have designed and projected a multitude of attachments, which with a reductionist criterion we can classify in axial attachments and in the Glossary of Oral and Maxillofacial Implants, referred to as a "special type of retentive mechanism formed by two corresponding and compatible components called patrix and matrix . Matrix refers to the component receptacle of the attachment and patrix to the portion having friction and fits and fits into the matrix.

\section{Attaches possibilities}

There is a multitude of possibilities when selecting the most appropriate attachment in each case, which in turn can be classified according to several criteria. The best known and used throughout history have been the bar-shaped attachments, magnet attachments, telescopic, ball-shaped and lastly, and resilient capacity and axial type locator. Locator type attachments are an anchoring system like all axial ones formed by a male and a female. The male, screwed to the implant, is cylindrical with variable height and on the occlusal side is milled a receptacle on which the female is positioned, formed in turn by a small hollow cylinder inside which goes an interchangeable plastic element (colloquially called shirt) which is introduced into the male receptacle and provides the retention. The ERA Attachment system though different is similar to the Locator. This type of attachment partially solves the drawbacks of ball type; On the one hand, it solves discrepancies of up to $40^{\circ}$ of disparalelismo between implants with just placing the shirt of green color in the female, although for greater discrepancy is preferable to use bars; And on the other hand it is possible to choose more or less retention capacity between a range of 1.5 pounds to 5 pounds (depending on the house), just change the color of the shirt transparent, pink, blue, green or red. It is currently the most frequently used system in professional practice and it is also the system chosen in this research project, so it is necessary to know more about its clinical performance. The Locator Attachment offers resilient retention by means of elastic connection and rotational movement and has low vertical height of the order of $3.7 \mathrm{~mm}$ with external hexagonal connection and $2.5 \mathrm{~mm}$ in implants with non-hexagonal connection. It is easy to use, such that the patient can place and remove the prosthesis with ease, without the need for a correct and sometimes complex alignment of the prosthesis. It can also be placed in overdentures with 2, 3 or 4 implants.

\section{Number and distribution of implants}

In the diagnosis and planning of the treatment of a fully edentulous arch by means of a supported implant restoration in any case, one of the most important decisions is to determine the number and location of the implants necessary to support the planned restoration; ${ }^{11}$ And although there are not enough prospective or retrospective clinical studies controlled in the literature to indicate this, there are at least recommendations, generally without sufficient scientific evidence, about the number of implants to be used. Recommendations for a fixed prosthesis solution range from the option that 4 implants are sufficient, to the opposite extreme in that the possibility that each missing tooth and even root is replaced by a Implant. ${ }^{12,13}$ This numerical variability sometimes has an economic base, since a smaller number of implants entails a cost savings for the patient and other anatomical or biological causes depending on the bone availability, which is especially critical in the posterior maxillary and mandibular sectors, In which, due to the patterns of bone reabsorption post-extraction and subsequent passage of time with conventional or non-conventional restorations, structures as important as the inferior alveolar nerve or the maxillary sinuses can be put at risk. However for a solution with an overdenture on two or four implants maximum, the availability of bone is not so critical and it is almost always possible to find in their places of location the necessary 7-9 $\mathrm{mm}$ of bone height and the minimum of $1 \mathrm{~mm}$ around of the implant in width. ${ }^{2-13}$ Although it is a fixed prosthesis or overdenture, in the present the improvement in the techniques of grafting and bone regeneration minimizes this problem since it allows the placement of implants in arcades with extreme resorptions that in last decades was not possible. On the other hand, for either option and regardless of what is said, as a rule, a greater number of implants is always preferable, even if only to better distribute the stress / tension avoiding localized areas that exceed the adaptation threshold. It is demonstrated and is a biomechanical principle that the overall stress on the entire implant/peri-implant bone system is reduced by increasing the area on which the force is applied and the most effective method to achieve this is to increase the number of implant supports prosthesis. In general, although the number of implants may vary depending on the type of prosthetic restoration, other parameters such as factors of patient strength, quantity and bone quality, prosthetic space, nature.

\section{No of implants}

Option with 1: The choice of a single implant in the midline sinfisaria finds its justification in those patients with limited economic resources and who for one reason or another have difficulties with their inferior conventional prostheses and so this solution has been proposed for a long time with satisfactory results in 21 Patients with five years of use or without follow-up data in nine patients. ${ }^{5}$ Even in a recent in vitro study it was shown that in both prostheses retained by one or two implants, lateral forces on the abutments were similar.

Option with 3 implants: The option of three implants for a mandibular overdenture is even less frequent; In the reviews of ${ }^{14}$ from 1997 to 2008 there are 8 references ( 2 and 6 ) for this situation, although the most current ones date back to 2004. They mainly supported bars of one type or another and some Ball or non-splinting designs and magnets. Look for these or other articles with three implants to see situation, are placed in pencil paper and are appointments of art 5 and 8 .

Option of 4 implants: Thus, the option of four implants as support for a mandibular overdenture has lost importance, with very few articles that in recent years have collected this form of treatment compared to 
only two implants; 4 of 49 in the review of Cehreli et al (2010a) of maintenance needs and 5 of 52 in peri-implant bone loss ${ }^{14}$ plus some isolated trial such as that of using 4 Implants in patients with anterior $\mathrm{V}$ arch.

Hybrid prostheses: constituent elements, number of implants, Dr. Maló technique parts and types.

Protocol all on four: 4 implants, modifying the angulation of the two most distal to the midline

Dental implants have become predictive therapeutic techniques, based on the protocol of Bränemark, ${ }^{3}$ for over 44 years, thanks to their studies and success rates throughout this period, during which they have been able to replace lost or missing teeth in adult patients. The all-on-four (all-on-4) technique, developed by Dr. Paulo Maló, is a system that allows complete rehabilitation with maxillary and/or mandibular implants in the toothless patient total. Its name comes from the use of 4 implants for maxilla, although 5 or 6 may be necessary in certain cases of the maxilla. One of the most attractive points of the technique is that they can be applied in a high percentage of cases with success rates above $95 \%$ (the lower implants will be interoperative even in situations of extreme resorption; In the upper jaw will be placed between the maxillary sinuses Reducing the need for regeneration that would contraindicate the technique). ${ }^{2,3}$ In addition, it is an intervention in which we place fewer implants than usual, which facilitates hygiene and, in addition, we lower costs. Focusing on the lower jaw, the philosophy of System is based on:

a. Use of four implants in the anterior interforaminal mandibular area.

b. Angulation of the posterior implants with the apices of the same towards the mesial, so that the insertion point can be placed in the vertical of the mentonians or, even, a little distal to them, in order to diminish the distal cantilever of the Future prosthesis.

In addition to the biomechanical risk of the aforementioned with reference to hybrid prostheses, other considerations, which may play a role of contraindication, must be taken into account:

a. It is essential to pay the utmost attention to the bases of the hybrid prosthesis to avoid the accumulation of food and bacterial plaque, which can lead to produce pathology in the peri-implant tissues.

b. Radiologic examination, catheterization, tone and appearance of soft tissues, as well as plaque and stone indices can be of great help in evaluating peri-implant tissues.

c. Maintenance should be performed, with periodic clinical and radiological controls, in patients with dental implants.

d. It is advisable to disassemble the prosthesis once a year, to proceed with its cleaning and polishing.

e. The patient should collaborate in his daily oral cleaning task, for which he has a great variety of means and auxiliary methods.

\section{Discussion hybrid surveys}

Regarding the distribution and location of the implants for a mandibular overdenture, in order to meet the conditions of stability and adequate occlusion, it is a general criterion to place the implants in the interforaminal region, in the space between the two mental foramina, in The area corresponding to the incisor-lateral teeth, canines and first premolars and thus for the option of two implants, are placed in the anterior part of the mandible, on both sides of the midline, preferably at the level of the canines and at a distance Of approximately $20 \mathrm{~mm}$, which gives better biomechanical conditions to prosthetic stability and adequate retention. According to Misch, ${ }^{2}$ with an overdenture retained by two implants at the level of the canines and a system of axial attachments in ball or not, good retention and stability is achieved for most of the masticatory functions, although with doubtful stability and mucous support mainly in the back, which greatly accelerates bone loss in this area. The advantages of the treatment of maxillary and mandibular edentulism with implant-supported prosthesis have been reported in the evidence, thus restoring function and esthetics, allowing patients to improve their social and psychological condition. ${ }^{15,16}$ Particular attention must be paid to the diagnostic phase, regardless of the technique used, surgical phase, occlusal and aesthetic aspects, as well as patient expectations. ${ }^{6}$ The rehabilitation of edentulous maxillae with osseointegrated implants has proven to be a highly predictable treatment over time. However, rehabilitation of partially or severely resorbed edentulous jaws presents anatomical limitations due to reduction of bone volume, particularly in the region of premolars and molars, so that distal cantilevers of up to $15 \mathrm{~mm}$ have been designed prosthetically, Have been shown to have a low success rate. ${ }^{15}$ Another modality is the installation of short implants which could be an alternative, but require a minimum amount of at least $7 \mathrm{~mm}$ of vertical bone height. They carried out reports of clinical cases where they concluded that due to the high success rate of osseointegrated implants the expectation of using them to replace the teeth with bad or reserved prognosis was created, for which a comprehensive diagnosis and the application of Techniques based and supported by scientific evidence. They propose that different treatment alternatives should be presented to the patient explaining the advantages and disadvantages of each option in relation to the biological and financial aspects where the patient chooses one of the possibilities presented. This information must be attached to the medical record for legal reasons. Biomechanical analysis of conventional implantsupported rehabilitation (2 stages) reveals that implant stress as a result of maladaptation of the prosthesis may be present after many years of osseointegration. ${ }^{9}$ For this reason, maladjustment may lead to problems such as screw loosening, prosthesis fracture or implants, and bone loss. ${ }^{10}$ Therefore, a precise fit between the implant abutment and supra-structure results in absence of stress, these factors are important for the long-term success of implant-supported restorations. Paulo Malo et al. ${ }^{2}$ introduced the 'All-on-Four' concept in 2003 with immediate loaded Bränemark implants. This protocol consists of the placement of 4 intermentonial implants of at least $10 \mathrm{~mm}$, the anterior two in the direction of the bone and the posterior two with an inclination of about $30^{\circ}$, emerging at the level of the second premolar. The hybrid prosthesis that supports the implants, after placement of angled abutments in the posterior fixations, replenishes the arcade to the first molar, and was placed before two hours after surgery. In the published paper, on 44 patients, they placed 176 implants of immediate loading (of which 45 were immediate) and 62 rescue implants. After a follow-up between 6 months and 2 years, they achieved a success rate of $96.7 \%$ and $100 \%$ of the prosthesis. According to the reviews reviewed, the type of prosthesis plays an important role in the results of implants loaded immediately. Widely demonstrated is the success of overdentures and inferior hybrid prostheses, with results similar to those of the load according to conventional protocols. ${ }^{16-18}$ Although the option of installing inclined implants bypassing the maxillary sinus 
pneumatization or severe reabsorption of the mandible proposed by Krekmanov ${ }^{12-14}$ and Malo, increase the possibility of installing longer implants, Improve the polygonal distribution of prosthetic support and reduce the number of implants without the need to perform a bone graft filling of the maxillary sinus. This option of tilting the implants can also be a surgical resource in the reabsorbed mandible placing the implants in the zone between the mental foramina, providing a viable and predictable alternative in the treatment of the severely reabsorbed mandible, reducing the number of implants, achieving a Efficient polygonal distribution capable of supporting 10 to 12 prosthetic replacement teeth and opting for the immediate prosthetic function modality, improving the acceptance of treatment by patients seeking replacement of their conventional prosthesis. ${ }^{18-20}$

\section{Conclusion}

It has been demonstrated that implant-supported prostheses are an excellent option for the rehabilitation of total edentulous patients, since it gives them function and aesthetics, which allows them to improve their social and psychological condition. It has also been observed that this type of prosthesis provides many advantages, among these advantages are: reduced bone loss, improved access to oral hygiene and more space to correct discrepancies in the dental arch ratio and also improves retention and stability Of the prosthesis. The demand for greater prosthetic stability by patients with complete dentures is a constant in daily clinical practice. Bone and economic limiting factors, among others, has made the treatment of choice in many cases are hybrid prostheses or overdentures. Frequently in clinical practice the factors to be taken into account are not clear, so the objective of this review is:

1. Concept and differences overdentures - hybrid prostheses.

2. Aspects for restorative choice.

3. Determine the situation, position and most favorable extension of the cantilever.

Therefore, and given the limitations of this review we can conclude:

1. Need to assess personal factors of the patient: sex, strength, arcade homologue and expectations.

2. Distal portion of posterior midline implants undergoes a greater load due to transmitted stress.

3. Option on 4 implants located in a blade offers a better biomechanical performance.

4. There is an absence of contrasted, and more long-term, evidence on the reduction or non-overloading of implant angulation, following the All on four protocols. ${ }^{20-39}$

\section{Funding}

None.

\section{Acknowledgments}

None.

\section{Conflicts of interest}

Author declares that there is no conflict of interest.

\section{References}

1. Gotfredsen K, Holm B. Implant-supported mandibular overdentures retained with ball or bar attachments: a randomized prospective 5-year study. Int J Prosthodont. 2000;13(2):125-130.

2. Misch CE. Densidad ósea: factor determinante en el plan de tratamiento. In: Misch CE, editor. Implantologia Contemporanea. 3rd ed, Spain: Elsevier; 2009. p. 130-146.

3. Eckert SE, Carr AB. Implant retained maxillary overdentures. Dent Clin N Am. 2004;48(3):585-601.

4. Visser A, Geertman ME, Meijer HJA. Five years of aftercare of implantretained mandibular overdentures and convencional dentures. J Oral Rehabil. 2002;29:113-120.

5. Geng JP, Tan K, Liu G. Application of finite element analysis in implant dentistry: a review of the literature. J Prosthet Dent. 2001;85(6):585-598.

6. Sahin S, Sehreli MC, Yalcin E. The influence of functional forceson the biomechanics of implant supported prostheses-a review. J Dent. 2002;30(7-8):271-282.

7. Bouazza K, Ijeilat E, Selva EJ, et al. Diseño y complicaciones de las sobredentaduras mandibulares retenidas mediante implantes. Quintessence. 2005;18:509-515.

8. Mallat-Dessplats E, Mallat-Callís E. Prótesis parcial removible $y$ sobredentaduras. Spain: Elsevier; 2003. p. 373-426.

9. Laney WR, Broggini N, Cochran DL. Glossary of Oral and Maxillofacial Implants. Qintessence, Germany; 2007.

10. Meijer HJ, Starmans FJ, Steen WH, et al. Three-dimensional, finiteelement analysis of bone around dental implants in an edentulous human mandible. Arch Oral Biol. 1993;38(6):491-496.

11. Curtis DA, Sharma A, Finzen FC, et al. Occlusal considerations for implant restorations in the partially edentolous Patient. $J$ Calif Dent Assoc. 2000;28(10):771-779.

12. Lekholm U, Zarb GA. Patient selection and preparation. In: BrnemaK, et al. editor. Tissue integrated prostheses: osseointegration in clinical dentistry. USA: Quintessence; 1985. p. 199-210.

13. Engelman MJ. Oseointegración. Diagnóstico clínico y alternativas restauradoras. Spain: Quintessence; 1998. p. 23-31.

14. Chang CL, Chen CS, Hsu ML. Biomechanical effect of platform switching in implant dentistry: a three-dimensional finite element analysis. Int $J$ Oral Maxillofac Implants. 2010;25(2):295-304.

15. Thomason JM, Feine J, Exley C, et al. Mandibular two implant-supported overdentures as the first choice standard of care for edentulous patientsthe York Consensus Statement. Br Dent J. 2009;207(4):185-186.

16. Feine JS, Carlsson GE, Awad MA, et al. The McGill consensus statement on overdentures. Mandibular two-implant overdentures as first choice standard of care for edentulous patients. Montreal, Quebec, May 24-25, 2002. Int J Oral Maxillofac Implants. 2002;17(4):601-602.

17. Hay JG. The biomechanics of sport techniques. New Jersey: PrenticeHall; 1985.

18. Fernandes dos Santos MB, Bacchi A, Correr-Sobrinho L, et al. The influence of clip material and cross sections of the bar framework associated with vertical misfit on stress distribution in implant-retained overdentures. Int J Prosthodont. 2014;27:26-32.

19. Ozan O, Ramoglu S. Effect of implant height differences on different attachment types and peri-implant bone in mandibular two-implant overdentures: 3D finite element study. J Oral Implantol. 2014;41(3):e50e59. 
20. Liu J, Pan S, Dong J, et al. Influence of implant number on the biomechanical behaviour of mandibular implant-retained/supported overdentures: a three-dimensional finite element analysis. $J$ Dent 2013;41(3):241-249.

21. Ohkubo C, Kurihara D, Shimpo H, et al. Effect of implant support on distal extension removable partial dentures: in vitro assessment. J Oral Rehabil. 2007;34(1):52-56.

22. Cunha LD, Pellizzer EP, Verri FR, et al. Evaluation of the influence of location of osseointegrated implants associated with mandibular removable partial dentures. Implant Dent. 2008;17(3):278-287.

23. Haruta A, Matsushita Y, Tsukiyama Y, et al. Effects of mucosal thickness on the stress distribution and denture stability of mandibular implantsupported overdentures with unsplinted attachments in vitro. $J$ Dent Biomech. 2011;894395.

24. Goto T, Nagao K, Ishida Y, et al. Influence of Matrix Attachment Installation Load on Movement and Resultant Forces in Implant Overdentures. J Prosthodont. 2015;24(2):156-163.

25. Manju V, Sreelal T. Mandibularbimplant-supported overdenture: an in vitro comparison of ball, bar and magnetic attachments. J Oral implantol. 2013;39:302-307.

26. Sertgöz A, Güvener S. Finite element analysis of the effect of cantilever and implant length on stress distribution in an implant-supported fixed prosthesis. J Prosthet Dent. 1996;76(2):165-169.

27. Christie TE. Cephalometric patterns of adults with normal occlusion. Angle Orthod. 1977;47:128-135.

28. Hsu ML, Chen FC, Kao HC, et al. Influence of Off-Axis Loading of an Anterior Maxillary Implant: A 3-D Finite Element Analysis. Int J Oral Maxillofac Implants. 2007;22(2):301-309.

29. Maeda Y, Miura J, Taki I, et al. Biomechanical analysis on platform switching: is there any biomechanical rationale? Clin Oral Implants Res. 2007;18(5):581-584

30. Rodríguez-Ciurana X, Vela-Nebot X, Segalà-Torres M, et al. The effect of interimplant distance on the height of the interimplant bone crest when using platform-switched implants. Int J Periodontics Restorative Dent. 2009;29(2):141-151
31. Schrotenboer J, Tsao YP, Kinariwala V, et al. Effect of microthreads and platform switching on crestal bone stress levels: a finite element analysis. J Periodontol. 2008;79(11):2166-2172.

32. Petrie CS, Williams JH. Probabilistic analysis of peri-implant strain predictions as influence by uncertainties in bone properties and oclusal forces. Clin Oral Implants Res. 2007;18(5):611-619.

33. Van Oosterwyck H, Duyck J, Vander Sloten J, et al. The influence of bone mechanical properties and implant fixation upon bone loading around implants. Clin Oral Implants Res. 1998;9(6):407-418.

34. Meijer HJ, Kuiper JH, Starmans FJ, et al. Stress distribution around dental implants: influence of superstructure, length of implants, and height of mandible. J Prosthet Dent. 1992;68(1):96-102.

35. Elsyad MA, Alokda MM, Gebreel AA. Effect of two designs of implantsupported overdentures on peri-implant and posterior mandibular bone resorptions: a 5-year prospective radiographic study. Clin Oral Implants Res. 2016.

36. Elsyad MA, Khairallah AS. Chewing efficiency and maximum bite force with different attachment systems of implant overdentures: a crossover study. Clin Oral Implants Res. 2016;28(6):677-682.

37. Elsyad MA, Mahanna FF, Elshahat MA. Locators versus magnetic attachment effect on peri-implant tissue health of immediate loaded two implants retaining a mandibular overdenture: a 1-year randomised trial. $J$ Oral Rehabil. 2016;43(4):297-305.

38. ELsyad MA, Setta FA, Khirallah AS. Strains around distally inclined implants retaining mandibular overdentures with Locator attachments. An in vitro study. J Adv Prosthodont. 2016;8(2):116-124.

39. Hee-Chul Kim, Janghyun Paek. Customized locator abutment fabrication on inclined implants: A clinical report. The Journal of Prosthetic Dentistry. 2017. 